\title{
Editorial
}

\section{Um ano de realizações}

Com este número, estamos finalizando um ano que, para nós da Revista de Psiquiatria do Rio Grande do Sul, foi pleno de satisfações e realizações. Neste ano, mantivemos o alto nível qualitativo dos artigos, assim como a regularidade da publicação, seguimos com uma linha editorial plural (que tem sido a marca registrada da Revista desde a sua fundação) e continuamos nos principais indexadores internacionais. Entretanto, fomos além: nossa Revista passou, este ano, a ser publicada totalmente na língua inglesa (em sua versão eletrônica no site do Scielo); renovamos parte de nossos Conselhos Editorial e Consultivo e pudemos comemorar com entusiasmo os 25 anos de publicação ininterrupta da Revista (com excelente evento científico e social e uma edição comemorativa). Desta forma, encerramos o ano de 2004 satisfeitos com o trabalho realizado e preparados para, em 2005, seguir na direção de manter o alto nível científico que a Revista tem perseguido.

O presente número, mais uma vez, traz aos leitores artigos com uma ampla abordagem de temas relevantes à prática psiquiátrica atual. Apresentamos cinco artigos originais. $O$ primeiro, de Norberto e Alejandra Marucco, da Argentina, enfoca a questão do poder na prática analítica atual. Os autores trazem idéias bastante originais e discutem situações de abuso de poder por parte do analista que podem ocorrer quando do processo analítico. O segundo artigo, do grupo do colega Gustavo Turecki, do Canadá, aborda, a partir de uma amostra de 168 casos de suicidas, a intrigante relação entre suicídio e a ausência de diagnóstico em eixo I, e chamam a atenção para o fato de que o método de autópsia psicológica realizado nesses casos pode falhar em detectar algum processo psiquiátrico subjacente comumente presente em pacientes suicidas. O terceiro artigo original, de Ygor Ferrão et al., descreve características clínicas e a história familiar de 111 pacientes com transtorno obsessivo-compulsivo oriundos do Hospital Presidente Vargas, de Porto Alegre. Este é mais um artigo fundamental no sentido de que as publicações brasileiras abram espaço para descrever as características das populações atendidas em nosso meio. $O$ quarto trabalho é um outro artigo na mesma linha, em que características peculiares de nossa população são descritas. Neste artigo, Primo \& Stein realizam um estudo transversal de base populacional com 1.044 indivíduos para identificar a prevalência de alcoolismo na cidade de Rio Grande (RS), chamando a atenção para a dificuldade de se realizar 
estudos populacionais sobre alcoolismo e a importante prevalência de $5,5 \%$ de abuso e de $2,5 \%$ de dependência na população estudada. O quinto e último artigo original, de Camargo \& Contel, reafirma o papel da nossa Revista enquanto um espaço privilegiado para publicações de instrumentos adaptados à nossa língua. Além de descrever a metodologia rigorosa utilizada na tradução e adaptação de questionários para a avaliação de habilidades e conhecimentos na prática psiquiátrica, o artigo disponibiliza aos nossos leitores um instrumento muito rico e interessante para a investigação tanto da prática quanto do ensino de psiquiatria.

Os três artigos de revisão não por acaso tratam de transtorno depressivo, tema cada vez mais relevante na prática psiquiátrica. O primeiro artigo, de Spanemberg \& Juruena, faz uma ótima revisão sobre as características históricas e nosológicas da distimia e sua relação com o transtorno depressivo maior. O segundo artigo, de Zimmermann, Carvalho \& Mari, aborda a questão da depressão e de outros fatores psicossociais que podem influenciar a evolução de pacientes acometidos por doença renal crônica, tema bastante importante especialmente para colegas que trabalham na chamada consultoria psiquiátrica. O terceiro artigo de revisão, de Júlia Trevisan, aborda o tema da depressão sob a ótica do papel da psicoterapia de orientação analítica em casos de depressão de difícil tratamento.

Apresentamos dois relatos de casos. Um é de Mariana Eizirik \& Bergmann e trata da repercussão da ausência paterna e seu impacto no desenvolvimento da criança e do adolescente. Essa abordagem é bastante importante e, muitas vezes, é esquecida pela valorização única da importância da ausência materna. O outro relato de caso, de Horimoto, Ayache \& Souza, estuda depressão secundária ao uso de interferon e de um novo antidepressivo, o escitalopram. Nossa Revista segue sendo um canal aberto para que os colegas continuem publicando seus relatos de caso, e, neste sentido, conclamamos que nossos leitores sigam enviando situações ocorridas em sua prática diária.

Finalizamos este número com a publicação de três resenhas de livros, demonstrando o rico momento editorial da psiquiatria brasileira. A primeira, de Rogéria Recondo, aborda o livro de Diogo Lara sobre Temperamento forte $e$ bipolaridade: dominando os altos e baixos do humor. A segunda resenha, de José Carlos de Souza, traz o importantíssimo tema do suicídio abordado no livro Tentativa de suicídio - um prisma para a compreensão da adolescência, de Enio Resmini. A última resenha, também escrita por José Carlos de Souza, trata da eletroconvulsoterapia a partir do livro dos colegas Sérgio Rigonatti, Moacyr Rosa \& Marina Rosa.

Apresentamos, portanto, aos nossos leitores, uma Revista plural, com dados originais a partir de amostras de pacientes brasileiros, com artigos de revisão que abordam temas relevantes à prática psiquiátrica cotidiana, com relatos de caso ricos e com resenhas de livros realizadas por colegas brasileiros de diversas regiões. Por tudo isso, temos certeza, o colega sentir-se-á satisfeito com o que estamos entregando neste número.

Desejamos a todos uma excelente leitura.

Flávio Shansis e Jacó Zaslavsky Editores 